\title{
Inhibition of return lasts longer at repeatedly stimulated locations than at novel locations
}

\author{
HSUAN-FU CHAO and YEI-YU YEH \\ National Taiwan University, Taipei, Taiwan
}

\begin{abstract}
Inhibition of return (IOR) refers to the fact that it takes longer for people to attend to recently examined locations than to novel locations. It has been argued that a single mechanism governs both IOR and negative priming (NP). If this is true, IOR and NP should share similar characteristics. Since NP depends on the use of repeated stimuli, in this study the dependence of IOR on repeated stimuli was explored. Experiments 1A-1D showed that, at longer cue-to-target-onset asynchrony (CTOA) intervals (613 and $906 \mathrm{msec}$ ), IOR could be observed only at repeatedly stimulated locations. However, IOR was observed when CTOA was short (253 msec) regardless of stimulus repetition. Experiments 2 and 3 replicated Experiments 1A-1D with a within-subjects design. The important role of memory representations in IOR is proposed.
\end{abstract}

To successfully and efficiently facilitate location of a target object in one's environment, one should utilize past experiences. This can be accomplished in multiple ways. One can learn the contingency between the target location and the search array (Chun \& Jiang, 1998). When items to be searched are presented at two different times, one can purposely search through new items (Belopolsky, Theeuwes, \& Kramer, 2005; Watson \& Humphreys, 1997). The phenomenon of inhibition of return (IOR), which originally referred to a slower response to a recently attended location than to an uncued location, suggests that people can choose to search an item that has not been searched recently. Furthermore, people may achieve this by selectively inhibiting the previously searched items (Klein \& MacInnes, 1999; Posner \& Cohen, 1984). In the present study, we investigated IOR to reveal how the inhibitory process influences behavior through the memory processes.

A cuing paradigm is generally used to study IOR. After the presence of an abrupt-onset cue, a target is presented either at the location previously occupied by the cue or at an uncued location. If the cue-to-target-onset asynchrony (CTOA) interval is short, a facilitatory effect is usually observed. Responses to targets at cued locations are faster than those to targets at uncued locations. If the CTOA interval is longer (e.g., more than $250 \mathrm{msec}$ ), responses to targets at cued locations are slower. It is hypothesized that attention is initially drawn to the cued location and then disengaged from that location, after which the previously searched location is inhibited, resulting in IOR (Posner \& Cohen, 1984).

The research and preparation of this article were supported by Taiwan National Science Council Grants NSC93-2917-I-002-005 (to H.-F.C.) and NSC92-2413-H-002-025 (to Y.-Y.Y.). We thank Hsiao-Chueh Chang for help in data collection. Correspondence should be sent to H.-F. Chao, Department of Psychology, National Taiwan University, No. 1, Sec. 4 , Roosevelt Road, Taipei, 106 Taiwan (e-mail: hfchao@ntu.edu.tw).
Inhibition has also been proposed as the mechanism of negative priming (NP; Tipper, 1985), which refers to a slowed response to previous distractors. Thus, it has been suggested that IOR and NP may share similar mechanisms (see, e.g., Buckolz, Boulougouris, O'Donnell, \& Pratt, 2002; Christie \& Klein, 2001; Houghton \& Tipper, 1994). For example, Houghton and Tipper developed a computational model of inhibition that accounts for both IOR and NP. Also, response to a previous target location was found to be slow in an NP paradigm, showing an IOR-like effect with an NP procedure (see, e.g., Christie \& Klein, 2001).

If the same inhibitory mechanism underlies both the IOR and NP, these two effects should follow the same operating principle. NP is usually contingent on stimulus repetition. The studies of Strayer, Grison, and colleagues (Grison \& Strayer, 2001; Malley \& Strayer, 1995; Strayer \& Grison, 1999) demonstrated the dependence of identity NP on the use of repeated identities. Chao and Yeh (2005) showed that location NP in a naming task was dependent on the use of repeated locations. Both identity NP and location NP could be observed only when the stimuli had been used many times in the experiment. According to Strayer, Grison, and their colleagues, the use of repeated stimuli is critical to NP because only high-activation distractors are subject to inhibition. Moreover, it was found that the use of repeated stimuli as probe distractors could increase interference in the probe trial, which was important for the observation of NP in a naming task (Chao, Yeh, \& Yang, 2003). However, it should be noted that NP has been found with novel shapes (DeSchepper \& Treisman, 1996; Loula, Kourtzi, \& Shiffrar, 2000; but see Strayer \& Grison, 1999), after one exposure of familiar objects (Grison, Tipper, \& Hewitt, 2005; Loula et al., 2000) and of faces (Grison et al., 2005), with repeated yet unfamiliar distorted stimuli (Nagai \& Yokosawa, 2003), and after one stimulus exposure in which two distractors competed for processing (Yee, 1991). When stimuli are distinct or when the competition from distrac- 
tors is high, NP can be observed with unfamiliar stimuli or after one stimulus exposure. Nevertheless, stimulus repetition has been reliably found as an important factor using the typical NP paradigm.

In the present study, we examined whether or not location repetition influences IOR. If IOR and NP share common mechanisms, the influence of location repetition on IOR is to be expected. The mediation of this effect by CTOA was also investigated in this study. If IOR was contingent on the use of repeated locations, there might be two reasons for this contingency. First, as an extension of Strayer and Grison's (1999) account for NP, only highly activated locations were inhibited. According to this hypothesis, the effect of location repetition on IOR should be independent of the CTOA, because only repeated locations with high activation are inhibited. Alternatively, we hypothesized that both the novel and the repeated locations are inhibited, whereas the inhibitory effect lasts longer at repeated than at unrepeated locations. This hypothesis extends the view that the inhibitory effect is stored in memory representations (e.g., visual spatial working memory, as suggested by Castel, Pratt, \& Craik, 2003) by emphasizing that representation stability can affect the duration of IOR. The memory research literature has indicated that episodic memory for familiar stimuli was better than that for novel stimuli (Korenman \& Peynircioğlu, 2004) and that shortterm memory span was larger when familiar words were to be remembered rather than unfamiliar words (Hulme, Maughan, \& Brown, 1991). We postulated in a representation durability hypothesis that stimulus repetition stabilizes memory representation of the inhibitory effect. As a result, the representations of the inhibitory effect should persist longer when repeated locations are used. According to this hypothesis, IOR should be affected by location repetition only when the CTOA is long.

\section{EXPERIMENTS 1A-1D}

To test the effect of location repetition, we used a method similar to that used in Chao and Yeh's (2005) Experiments 3 and 4 . In the present experiments, there were four blocks, each of which had a unique set of four locations. More importantly, each block was divided into halves, resulting in a cue type (valid vs. invalid) $\times$ half (first vs. second) design. In the first half of each of the four blocks, the four locations were relatively novel in comparison to those of the second half. In the second half, after repetitive use of the same set of locations, each location was more familiar than the locations in the first half. The contrast between the first and second halves demonstrates the effect of location repetition on IOR.

The duration of CTOA was tested across Experiments $1 \mathrm{~A}-1 \mathrm{D}$. In Experiment 1A, a CTOA interval of $107 \mathrm{msec}$ was used to investigate whether or not there was any difference between the novel and repeated locations in a facilitatory cuing effect. In Experiments 1B, 1C, and 1D, CTOA intervals of 253, 613, and $906 \mathrm{msec}$, respectively, were tested to examine the IOR effect for the novel and repeated locations at different CTOA intervals.

\section{Method}

Participants. A total of 84 undergraduate students at National Taiwan University participated in these experiments for bonus credit in an introductory psychology course. All the participants were naive as to the purpose of the experiments and had normal or corrected-tonormal vision. There were 21 participants in each experiment.

Stimuli. Locations were selected from an invisible $15 \times 15$ matrix. The matrix was located in the center of the screen. Each cell of the matrix had a width of $1.1^{\circ}$ and a height of $1.1^{\circ}$ from a viewing distance of about $60 \mathrm{~cm}$. The cue was the white outline of a cell, with a border thickness of $0.2^{\circ}$. The probe was a white dot presented at the center of a cell.

Four sets of four locations were selected under the constraint that the minimum distance between any two locations should be $3.5^{\circ}$. The locations in each stimulus set formed an invisible square centered on the screen. One set of four locations was used repeatedly in each block.

Procedure. A computer with an Intel Pentium III processor was used. The refresh rate of the 17-in. CRT monitor was $13.33 \mathrm{msec}$. The experiments were run by DMDX software (Forster \& Forster, 2003). In each experiment, there were four blocks and 20 trials in each half of each block. Four were valid trials, 12 were invalid trials, and the remaining 4 were catch trials. Therefore, the cue could not predict the location of the probe but could capture attention by its onset. All trials within a half block were presented in a random sequence. Pooling these trials from the four blocks resulted in a total of 16 trials in each half for the valid condition, a total of 48 trials in each half for the invalid condition, and a total of 16 catch trials. The participants received 12 practice trials before the experiments.

In each trial, a white cross at the center of the screen and a "ding" sound were simultaneously presented as warning signals and disappeared after $293 \mathrm{msec}$. After $107 \mathrm{msec}$, a cue appeared, followed by either the target (in Experiments 1A and 1B) or a second fixation and then the target (in Experiments $1 \mathrm{C}$ and 1D). The overall CTOAs were approximately 107, 253, 613, and $906 \mathrm{msec}$ for Experiments 1A, $1 \mathrm{~B}, 1 \mathrm{C}$, and 1D, respectively. The displays during this time consisted of $53 \mathrm{msec}$ of cue and $54 \mathrm{msec}$ of blank screen (Experiment 1A); $200 \mathrm{msec}$ of cue and $53 \mathrm{msec}$ of blank screen (Experiment 1B); $200 \mathrm{msec}$ of cue, $107 \mathrm{msec}$ of blank screen, $200 \mathrm{msec}$ of fixation cross, and $107 \mathrm{msec}$ of blank screen (Experiment 1C); and $200 \mathrm{msec}$ of cue, $107 \mathrm{msec}$ of blank screen, $200 \mathrm{msec}$ of fixation cross, and $400 \mathrm{msec}$ of blank screen (Experiment 1D). The target was presented until either the participant responded or $1,000 \mathrm{msec}$ had elapsed. The intertrial interval was $1,000 \mathrm{msec}$. The participants were instructed to press the left button of the mouse when a white dot appeared.

\section{Results}

In these and all subsequent experiments, outliers were excluded by the criterion following Van Selst and Jolicour's (1994) method. A total of $2.2 \%, 2.5 \%, 2.2 \%$, and $2.8 \%$ of the trials were treated as outliers in Experiments $1 \mathrm{~A}, 1 \mathrm{~B}, 1 \mathrm{C}$, and 1D, respectively. Each experiment involved a cue type (valid vs. invalid) $\times$ half (first vs. second) design. Mean correct response times (RTs) and accuracies were analyzed by a $2 \times 2$ repeated measures ANOVA and are presented in Table 1. Figure 1 shows the cuing effect in these four experiments.

Experiment 1A. As Table 1 shows, responses to a valid location were marginally faster than those to invalid locations $\left[F(1,20)=3.9, M S_{\mathrm{e}}=508.9, p=.06\right]$. Furthermore, given that the interaction was not significant $\left(F<1, M S_{\mathrm{e}}=90.6\right)$, there was no difference in the cuing effect between the first and second halves. Accuracies were not analyzed because they were at $100 \%$ for each condition. 
Table 1

Mean Correct Response Times (RTs, in Milliseconds) and Accuracies (\%) in Each Condition of Experiments 1A-1D

\begin{tabular}{|c|c|c|c|c|c|c|c|c|}
\hline \multirow[b]{4}{*}{ Half } & \multicolumn{8}{|c|}{ Cue Type } \\
\hline & \multicolumn{4}{|c|}{ Valid } & \multicolumn{4}{|c|}{ Invalid } \\
\hline & \multicolumn{2}{|c|}{ RT } & \multicolumn{2}{|c|}{ Accuracy } & \multicolumn{2}{|c|}{ RT } & \multicolumn{2}{|c|}{ Accuracy } \\
\hline & $M$ & $S D$ & $M$ & $S D$ & $M$ & $S D$ & $M$ & $S D$ \\
\hline \multicolumn{9}{|c|}{ Experiment 1A: 107-msec CTOA } \\
\hline First & 339.7 & 35.6 & 100.0 & 0.0 & 348.2 & 52.1 & 100.0 & 0.0 \\
\hline Second & 341.0 & 44.5 & 100.0 & 0.0 & 351.9 & 54.6 & 100.0 & 0.0 \\
\hline \multicolumn{9}{|c|}{ Experiment 1B: 253-msec CTOA } \\
\hline First & 370.8 & 70.5 & 99.4 & 2.8 & 354.9 & 63.8 & 99.0 & 4.5 \\
\hline Second & 369.6 & 74.9 & 99.7 & 1.3 & 354.0 & 77.3 & 98.7 & 5.4 \\
\hline \multicolumn{9}{|c|}{ Experiment 1C: 613-msec CTOA } \\
\hline First & 359.5 & 53.2 & 100.0 & 0.0 & 358.5 & 60.3 & 99.7 & 0.7 \\
\hline Second & 359.9 & 59.6 & 99.7 & 1.3 & 349.0 & 54.5 & 99.9 & 0.4 \\
\hline \multicolumn{9}{|c|}{ Experiment 1D: 906-msec CTOA } \\
\hline First & 353.7 & 61.4 & 100.0 & 0.0 & 355.7 & 69.0 & 100.0 & 0.0 \\
\hline Second & 359.7 & 71.2 & 99.7 & 1.3 & 349.5 & 64.4 & 100.0 & 0.0 \\
\hline
\end{tabular}

Note-CTOA, cue-to-target-onset asynchrony.

The results showed that cues at both the novel and repeated locations could attract attention with equal magnitude. Thus, any findings of the dependence of IOR on repeated locations cannot be accounted for by the inability of a cue to capture attention at a novel location.

Experiment 1B. The results showed that IOR occurred with nonrepeated and repeated locations when CTOA was $253 \mathrm{msec}$. As is shown in Table 1, responses to valid locations were slower than those to invalid ones $[F(1,20)=$ 34.8, $\left.M S_{\mathrm{e}}=149.6, p<.01\right]$. Furthermore, there was no difference in the IOR effect between the first and second halves $\left(F<1, M S_{\mathrm{e}}=75.1\right)$. Analysis of accuracy revealed no significant effect $(p s>.20)$.
Experiment 1C. IOR was affected by location repetition when the CTOA was $613 \mathrm{msec}$. IOR occurred only in the second half $\left[F(1,40)=12.4, M S_{\mathrm{e}}=100.9, p<.01\right]$ and not in the first half $(F<1$; see Figure 1). This pattern was supported by the significant cue type $\times$ half interaction $\left[F(1,20)=6.8, M S_{\mathrm{e}}=76.5, p<.05\right]$. Accuracies were analyzed in the same manner, and no effect was significant $(p \mathrm{~s}>.20)$.

Experiment 1D. The 906-msec CTOA used in Experiment 1D replicated the results of Experiment 1C (see Figure 1). IOR occurred only in the second half $[F(1,40)=$ $\left.6.9, M S_{\mathrm{e}}=155.1, p<.05\right]$ and not in the first half $(F<1)$. This pattern was supported by the significant cue type $\times$ half interaction $\left[F(1,20)=4.9, M S_{\mathrm{e}}=157.2, p<.05\right]$. Accuracy was at $100 \%$ for all but 1 participant. Analysis of accuracies revealed no significant effect $(p s>.20)$.

As a whole, results of these experiments indicate that IOR was affected by location repetition when the CTOA was long but not when it was short. These findings supported our hypothesis of the important role of representation durability in IOR.

\section{EXPERIMENT 2}

The results of Experiments 1A-1D indicate that location repetition can affect the effect of IOR. Moreover, the CTOA was a key factor in determining whether or not location repetition could influence IOR. These findings are consistent with our representation durability hypothesis. Experiment 2 was conducted to replicate the importance of CTOA and location repetition in IOR with all the factors manipulated as within-subjects variables. To shorten the experiment, only two CTOAs (253 and $613 \mathrm{msec}$ ) were used. Moreover, a procedural difference between short and long CTOAs in Experiments 1A-1D was con-

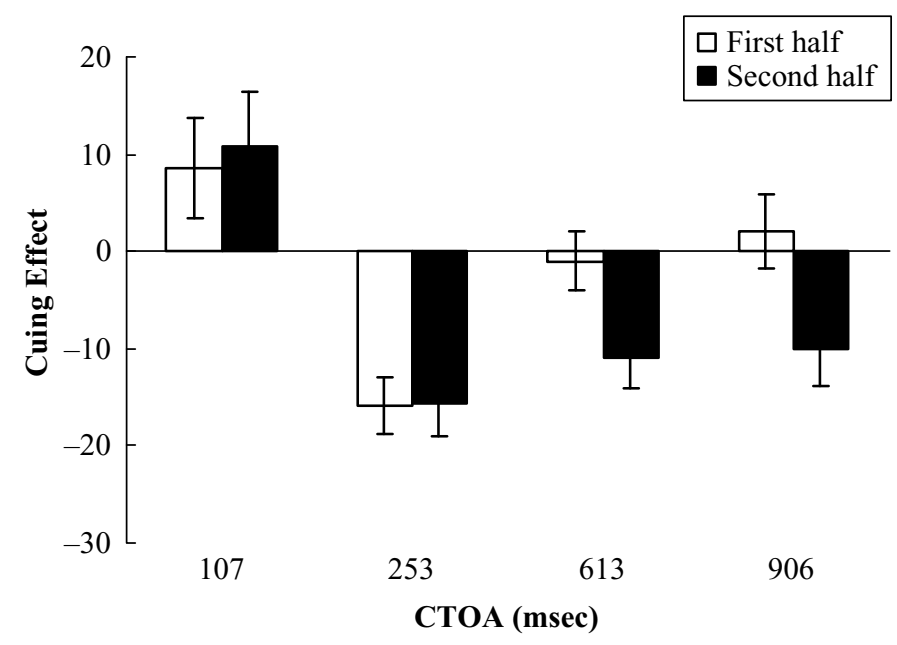

Figure 1. Cuing effect in the first and second halves of the blocks as a function of cue-to-target-onset asynchrony (CTOA) in Experiments 1A1D. The CTOAs were 107, 253, 613, and $906 \mathrm{msec}$ in Experiments 1A, 1B, 1C, and 1D, respectively. Error bars represent standard errors. 
trolled in this experiment. Previously, the peripheral cue had been followed by a fixation cue when CTOA was long (Experiments 1C and 1D) but not when it was short (Experiments 1A and 1B). With some modifications, a fixation cue was included in all the conditions of the present experiment.

\section{Method}

Participants. Twelve undergraduate students at National Taiwan University participated in this experiment for bonus credit in an introductory psychology course. All the participants were naive as to the purpose of the experiment and had normal or corrected-tonormal vision.

Stimuli. The preparation of the stimuli was similar to that of the stimuli in Experiments 1A-1D. Unlike in each of Experiments 1A$1 \mathrm{D}$, eight sets of four locations were selected under the constraint that no two locations of the same set should be too close to each other. The minimum distance between any two locations within a set was $2.2^{\circ}$.

Procedure. There were eight blocks in this experiment, and the CTOA was manipulated across blocks. For half of the participants, the CTOA of the first four blocks was $253 \mathrm{msec}$ whereas that of the last four blocks was $613 \mathrm{msec}$. The order was reversed for the other half of the participants.

The time course of a trial was identical to that of Experiments 1B or $1 \mathrm{C}$ except for the following modifications: When the CTOA was $253 \mathrm{msec}$, immediately after presentation of the peripheral cue a fixation cue was presented at the center of the screen for $53 \mathrm{msec}$. For the 613-msec CTOA, the cue-target interval consisted of a blank screen $(173 \mathrm{msec})$, a fixation cross $(53 \mathrm{msec})$, and a blank screen (187 msec).

\section{Results and Discussion}

A total of $2.8 \%$ of the trials were excluded as outliers. This experiment involved a cue type (valid vs. invalid) $\times$ half (first vs. second) $\times$ CTOA (253 vs. $613 \mathrm{msec}$ ) design. Mean correct RTs and accuracies are presented in Table 2 . Mean RTs were analyzed by a $2 \times 2 \times 2$ repeated measures ANOVA. Accuracies were not analyzed because only 4 participants had one error each. Figure 2 shows the cuing effect in each condition.

The results replicated the findings of Experiment 1 . When the CTOA was short (253 $\mathrm{msec})$, location repetition did not influence the effect of IOR. However, when the it was long $(613 \mathrm{msec})$, IOR was observed only with repeated locations. The main effect of CTOA was significant $\left[F(1,11)=9.4, M S_{\mathrm{e}}=1,656.7, p<.05\right]$, indicating that responses were slower when the CTOA was $253 \mathrm{msec}$. The main effect of cue type revealed the effect of IOR $\left[F(1,11)=10.0, M S_{\mathrm{e}}=371.7, p<.01\right]$. There was a CTOA $\times$ half interaction $\left[F(1,11)=6.0, M S_{\mathrm{e}}=814.1\right.$, $p<.05]$. More importantly, the three-way interaction was significant $\left[F(1,11)=9.7, M S_{\mathrm{e}}=138.8, p<.01\right]$. Planned comparisons revealed that when the CTOA was $253 \mathrm{msec}$, IOR was observed in the first $[F(1,44)=10.8$, $\left.M S_{\mathrm{e}}=291.87, p<.01\right]$ and second $[F(1,44)=4.5, p<$ .05] halves; when the CTOA was $613 \mathrm{msec}$, IOR was observed only in the second half $[F(1,44)=5.9, p<.05]$.

\section{EXPERIMENT 3}

To further replicate the finding that location repetition was critical to IOR when the CTOA was long, this experi- ment was identical to Experiment 2 except that trials of different CTOAs were intermixed within each block rather than run in different blocks.

\section{Method}

Sixteen undergraduate students at National Taiwan University participated in this experiment for bonus credit in an introductory psychology course. All of the participants were naive as to the purpose of the experiment and had normal or corrected-to-normal vision. This experiment was identical to Experiment 2 with one exception: Within each block, the CTOA was $253 \mathrm{msec}$ in half of the trials and $613 \mathrm{msec}$ in the other half.

\section{Results and Discussion}

A total of $3.1 \%$ of the trials were excluded as outliers. This experiment involved a cue type (valid vs. invalid) $\times$ half (first vs. second) $\times$ CTOA (253 vs. 613) design. Mean RTs and accuracies were analyzed by a $2 \times 2 \times 2$ repeated measures ANOVA and are presented in Table 3. Figure 2 shows the cuing effect in each condition.

The main effect of CTOA was significant $[F(1,15)=$ 84.5, $\left.M S_{\mathrm{e}}=741.4, p<.01\right]$, indicating that responses were slower when the CTOA was $253 \mathrm{msec}$ than when it was $613 \mathrm{msec}$. The main effect of cue type revealed the IOR effect $\left[F(1,15)=11.9, M S_{\mathrm{e}}=444.3, p<.01\right]$; other effects were not significant $(p \mathrm{~s}>.10)$. Planned comparisons revealed that when the CTOA was $253 \mathrm{msec}$, IOR was observed in the first $\left[F(1,60)=4.8, M S_{\mathrm{e}}=391.47\right.$, $p<.05]$ and second $[F(1,60)=5.5, p<.05]$ halves; when CTOA was $613 \mathrm{msec}$, IOR was observed in the second half only $[F(1,60)=5.9, p<.05]$. These contrasts confirmed that IOR was modulated by location repetition when CTOA was long (613 msec). Analysis of accuracies revealed no significant effect $(p s>.10)$.

\section{GENERAL DISCUSSION}

This study demonstrated that IOR was contingent on location repetition and that this dependence was modulated by CTOA. When the CTOA was short (253 msec), IOR was not influenced by location repetition. When the CTOA was long (613 or $906 \mathrm{msec}$ ), IOR was observed only at repeated locations.

Table 2

Mean Correct Response Times (RTs, in Milliseconds) and Accuracies (\%) in Each Condition of Experiment 2

\begin{tabular}{|c|c|c|c|c|c|c|c|c|}
\hline \multirow[b]{4}{*}{ Half } & \multicolumn{8}{|c|}{ Cue Type } \\
\hline & \multicolumn{4}{|c|}{ Valid } & \multicolumn{4}{|c|}{ Invalid } \\
\hline & \multicolumn{2}{|c|}{ RT } & \multicolumn{2}{|c|}{ Accuracy } & \multicolumn{2}{|c|}{ RT } & \multicolumn{2}{|c|}{ Accuracy } \\
\hline & $M$ & $S D$ & $M$ & $S D$ & $M$ & $S D$ & $M$ & $S D$ \\
\hline \multicolumn{9}{|c|}{ 253-msec CTOA } \\
\hline First & 425.1 & 51.5 & 100.0 & 0.0 & 402.2 & 50.1 & 99.8 & 0.6 \\
\hline Second & 409.6 & 48.4 & 99.0 & 2.4 & 394.8 & 62.6 & 99.8 & 0.6 \\
\hline \multicolumn{9}{|c|}{ 613-msec CTOA } \\
\hline First & 371.4 & 60.8 & 100.0 & 0.0 & 376.3 & 42.1 & 100.0 & 0.0 \\
\hline Second & 399.5 & 75.2 & 100.0 & 0.0 & 382.6 & 62.4 & 99.0 & 3.0 \\
\hline
\end{tabular}




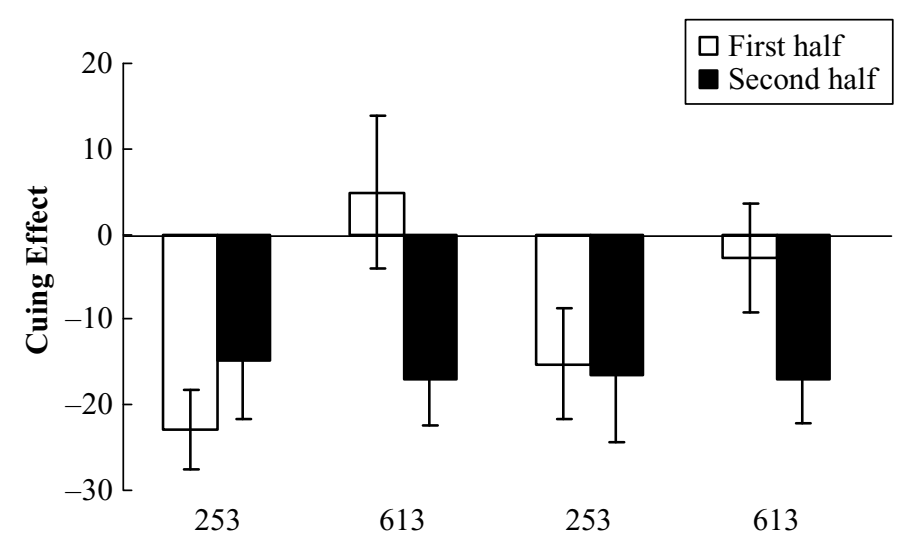

Experiment 2

Experiment 3

CTOA (msec)

Figure 2. Cuing effect in the first and second halves of the blocks as a function of cue-to-target-onset asynchrony (CTOA) in Experiments 2 and 3. Error bars represent standard errors.

These results support the representation durability hypothesis. The inhibitory process acts on a stimulus's internal representations. Each occurrence leaves a trace of the inhibitory process. As a result, the representation of the inhibitory process on the repeated locations becomes more stable than its representation on the nonrepeated locations. With a durable memory representation, the inhibitory effect can persist for a long time. Thus, IOR lasted longer at repeated locations than at novel locations.

According to this hypothesis, any factor that stabilizes the inhibited representations should enable IOR to be observed more easily. For example, IOR should be more easily observed when there is continuous input from the external environment. When the search scene or the search display was kept on the screen (Klein \& MacInnes, 1999; Takeda \& Yagi, 2000), IOR in a visual search task could be found, in contrast to the situation in which the scene or placeholders were not presented on the screen constantly. Also, when distinctive faces were cued, IOR could last as long as 13 min (Tipper, Grison, \& Kessler, 2003). Therefore, both the maintenance and the retrieval of the repre-

Table 3

Mean Correct Response Times (RTs, in Milliseconds) and Accuracies (\%) in Each Condition of Experiment 3

\begin{tabular}{|c|c|c|c|c|c|c|c|c|}
\hline \multirow[b]{4}{*}{ Half } & \multicolumn{8}{|c|}{ Cue Type } \\
\hline & \multicolumn{4}{|c|}{ Valid } & \multicolumn{4}{|c|}{ Invalid } \\
\hline & \multicolumn{2}{|c|}{ RT } & \multicolumn{2}{|c|}{ Accuracy } & \multicolumn{2}{|c|}{ RT } & \multicolumn{2}{|c|}{ Accuracy } \\
\hline & $M$ & $S D$ & $M$ & $S D$ & $M$ & $S D$ & $M$ & $S D$ \\
\hline \multicolumn{9}{|c|}{ 253-msec CTOA } \\
\hline First & 477.9 & 60.6 & 98.7 & 4.6 & 462.7 & 60.4 & 97.7 & 6.3 \\
\hline Second & 473.4 & 58.1 & 98.0 & 5.0 & 456.9 & 59.9 & 98.3 & 4.2 \\
\hline \multicolumn{9}{|c|}{ 613-msec CTOA } \\
\hline First & 426.1 & 48.9 & 99.5 & 1.7 & 423.3 & 54.7 & 99.2 & 3.1 \\
\hline Second & 430.2 & 57.8 & 99.2 & 3.1 & 413.3 & 51.8 & 99.3 & 1.7 \\
\hline
\end{tabular}

sentation may influence how the inhibitory process affects behavior.

What might be the basis for the memory representations of inhibitory processes in the present task context? A potential candidate is spatial working memory. IOR can be reduced under the load of spatial working memory (Castel et al., 2003; Chou \& Yeh, 2005). However, the effect of long-term IOR (see, e.g., Tipper et al., 2003) could hardly be attributed to working memory. Further investigation into the dissociation of the memory effect on short- and long-term IORs should clarify this issue.

The dependence of IOR on repeated stimuli was not limited to the use of locations. Following Fuentes, Vivas, and Humphreys (1999), Weger and Inhoff (2006) presented a prime word followed by an unrelated intervening word. After a delay, a target word was presented. The target word may or may not have been related to the category of the prime word. Semantic IOR was defined as a slowing of responses to targets related to the prime words in comparison to responses to targets that were not related to the primes. Their Experiments 1 and 2 indicated that semantic IOR was contingent on stimulus repetition. Semantic IOR was not found in the first block but was observed in later blocks.

It may be premature to conclude that IOR and NP have a common mechanism. It is important to study the time course of NP for nonrepeated and repeated stimuli. However, this study provides supporting evidence for the claim that IOR and NP share a mechanism.

\section{REFERENCES}

Belopolsky, A. V., Theeuwes, J., \& Kramer, A. F. (2005). Prioritization by transients in visual search. Psychonomic Bulletin \& Review, 12, 93-99.

Buckolz, E., Boulougouris, A., O'Donnell, C., \& Pratt, J. (2002). Disengaging the negative priming mechanism in location tasks. European Journal of Cognitive Psychology, 14, 207-225.

Castel, A., Pratt, J., \& Craik, F. I. M. (2003). The role of spatial 
working memory in inhibition of return: Evidence from divided attention tasks. Perception \& Psychophysics, 65, 970-981.

Chaо, H.-F., \& Yен, Y.-Y. (2005). Location negative priming in identity discrimination relies on location repetition. Perception \& Psychophysics, 67, 789-801.

CHAO, H.-F., YeH, Y.-Y., \& YANG, T.-Y. (2003). Interference and inhibition of distractors. Chinese Journal of Psychology, 45, 361-377.

Chou, W. L., \& YeH, S. L. (2005, August). Dissociation of object- and space-based inhibition of return by working memory. Poster presented at the 28th European Conference on Visual Perception, La Coruña, Spain.

Christie, J., \& KLeIN, R. M. (2001). Negative priming for spatial locations? Canadian Journal of Experimental Psychology, 55, 24-38.

Chun, M. M., \& JiAng, Y. (1998). Contextual cueing: Implicit learning and memory of visual context guides spatial attention. Cognitive Psychology, 36, 28-71.

DeSchepper, B., \& Treisman, A. (1996). Visual memory for novel shapes: Implicit coding without attention. Journal of Experimental Psychology: Learning, Memory, \& Cognition, 22, 27-47.

Forster, K. I., \& Forster, J. C. (2003). DMDX: A Windows display program with millisecond accuracy. Behavior Research Methods, Instruments, \& Computers, 35, 116-124.

Fuentes, L. J., Vivas, A. B., \& Humphreys, G. W. (1999). Inhibitory mechanisms of attentional networks: Spatial and semantic inhibitory processing. Journal of Experimental Psychology: Human Perception \& Performance, 25, 1114-1126.

Grison, S., \& STRAYER, D. L. (2001). Negative priming and perceptual fluency: More than what meets the eye. Perception \& Psychophysics, 63, 1063-1071.

Grison, S., TipPer, S. P., \& HewitT, O. (2005). Long-term negative priming: Support for retrieval of prior attentional processes. Quarterly Journal of Experimental Psychology, 58A, 1199-1224.

Houghton, G., \& Tipper, S. P. (1994). A model of inhibitory mechanisms in selective attention. In D. Dagenbach \& T. Carr (Eds.), Inhibitory processes in attention, memory, and language (pp. 53-112). San Diego: Academic Press.

Hulme, C., Maughan, S., \& Brown, G. D. (1991). Memory for familiar and unfamiliar words: Evidence for a long-term memory contribution to short-term memory span. Journal of Memory \& Language, 30, 685-701.

KLEIN, R. M., \& MacInNES, W. J. (1999). Inhibition of return is a foraging facilitator in visual search. Psychological Science, 10, 346-352.
Korenman, L. M., \& PeynircioğLU, Z. F. (2004). The role of familiarity in episodic memory and metamemory for music. Journal of Experimental Psychology: Learning, Memory, \& Cognition, 30, 917-922.

Loula, F., KourtzI, Z., \& ShIFfrar, M. (2000). Surface segmentation cues influence negative priming for novel and familiar shapes. Journal of Experimental Psychology: Learning, Memory, \& Cognition, 26, 929-944.

Malley, G. B., \& Strayer, D. L. (1995). Effect of stimulus repetition on positive and negative identity priming. Perception \& Psychophysics, 57, 657-667.

NagaI, J.-I., \& YoKosawa, K. (2003). Negative priming and stimulus familiarity: What causes opposite results? Memory \& Cognition, 31, 369-379.

PosNer, M. I., \& CoHEN, Y. (1984). Components of visual orienting. In H. Bouma \& D. G. Bouwhuis (Eds.), Attention and performance X: Control of language processes (pp. 531-556). Hillsdale, NJ: Erlbaum.

StraYer, D. L., \& Grison, S. (1999). Negative identity priming is contingent on stimulus repetition. Journal of Experimental Psychology: Human Perception \& Performance, 25, 24-38.

TAKEDA, Y., \& YAGI, A. (2000). Inhibitory tagging in visual search can be found if search stimuli remain visible. Perception \& Psychophysics, 62, 927-934.

TIPPER, S. P. (1985). The negative priming effect: Inhibitory priming by ignored objects. Quarterly Journal of Experimental Psychology, 37A, 571-590.

TipPer, S. P., Grison, S., \& KessLer, K. (2003). Long-term inhibition of return of attention. Psychological Science, 14, 19-25.

Van Selst, M., \& Jolicceur, P. (1994). A solution to the effect of sample size on outlier elimination. Quarterly Journal of Experimental Psychology, 47A, 631-650.

Watson, D. G., \& Humphreys, G. W. (1997). Visual marking: Prioritizing selection for new objects by top-down attentional inhibition of old objects. Psychological Review, 104, 90-122.

WEGER, U. W., \& INHOFF, A. W. (2006). Semantic inhibition of return is the exception rather than the rule. Perception \& Psychophysics, 68, 244-253.

YEe, P. L. (1991). Semantic inhibition of ignored words during a figure classification task. Quarterly Journal of Experimental Psychology, 43A, 127-153.

(Manuscript received October 22, 2004; revision accepted for publication March 12, 2006.) 